\title{
Music is a Gateway to the Soul: Exploring Ways of Utilising Music and Song Projects in Promoting Foreign Language Learning
}

\begin{abstract}
ALFRED NDHLOVU
"Language and Music are two ways that human beings use to communicate and express themselves through sound".
\end{abstract}

-Khaghaninejad and Fahandejsaadi

\section{Abstract}

Numerous articles have been written on the role of music in language learning. The contribution of various scholars of different backgrounds in acknowledging the significance of music in promoting language learning is indeed astounding and encouraging. One would then wonder what new contribution in this already swelling body of information that this article seeks to provide. First of all, this study seeks to discuss practical or rather pedagogical strategies by which music can be utilised to promote foreign language learning. The approach employed in this study is quite unique in the sense that translation is taken as the gateway through which music can be harnessed to improve foreign language learning. The view that is central in this discussion is that, since music is understood as a universal language that cuts across different age groups, social and cultural structures, channelling translation based activities towards music can be a powerful method of foreign language learning. Rather than simply singing and rehearsing target language songs, learners can be given tasks and projects of translating target language songs into their L1/L2 and performing their work in classroom activities. In such activities, learners are given an opportunity of not only enjoying the process of foreign language learning but most importantly of localising the language experience into their lifestyle, thus domesticating the foreign. For instance, giving them an opportunity to use the target language learning material to compile songs which 
they can translate and perform (both the original and the translated version) in front of other learners and the teacher, may give them the satisfaction of being the producers of their projects. Their chances of having an intimate relationship with their lyrics may be the much needed bond between the learner and the target language. In the context of this study, such projects are referred to as foreign language learning music/song projects. This discussion also encourages the utilisation of digitization in the performance of music/song projects. Hence, utilizing various applications that can be used to edit music (mini studios), music/song projects can be transformed into enjoyable activities, where learners may even forget that they are learning a foreign language and thus paving a way to a process of acquiring the target language rather than merely learning it.

Keywords: Music, Translation and Foreign Language Learning.

\section{Introduction}

The main concern of this study is to explore the means by which music and song projects can be utilised to promote foreign language learning. First of all, the study is in cognisance of the fact that in foreign language learning contexts, learning of the target language is mainly limited to the classroom environment. Hence, music/song projects need to benefit learners during their classroom learning experience. In the context of this study, music/song projects refer to activities whereby learners (under the guidance of their foreign language teachers), engage in performative projects, which involve planning, rehearsing and performing songs both in the target language and the first or national language. When doing these projects, learners need to be given autonomy to exercise or express their creativity. Rather than teachers bringing a list of selected songs into the classroom, learners are encouraged to choose one target language song to be translated and performed in front of the class. Translation and Singability 
therefore, play a major role in these activities since performance is key. The study will therefore, begin by discussing the significance of music and songs in foreign language learning, before exploring theoretical concepts of translation and singability. It will also discuss issues related to the pedagogical implementation of music/song projects, and suggestions on how to maximise on the use of these projects to improve foreign language learning.

\subsection{Music/Songs: Contribution in Foreign Language Learning}

\subsubsection{Defining Music/Songs}

Providing a concise definition that can embrace every work of art that deserves to be referred to as "music" or "song" is a challenging activity. Many definitions therefore, are classified as either too wide or general or too narrow and exclusive. What makes defining music a complex task is that various individuals define it from the point of view of their major areas of study and influence. For instance, to biologists such as Dorrell, music needs to be defined in terms of its purpose of making people "feel good". It is "something that people create and something that people respond to" (Dorrell 2005: 19). Some definitions, such as Levinson's (1990), view music as a set of organised sounds with a purpose of enriching or intensifying experience through active engagement (e.g listening, dancing, performing). Although one may argue that music does not necessarily need to draw attention upon itself, one has to be also aware that, as long as it is meant to be listened to, music is likely to thrive from attention. Furthermore, what makes Levinson's definition interesting is that it views music as activity based and not just sound (i.e being enriched by listening, dancing and performance). 
Since it is not the intention of this study to fully pursue the discussion of various definitions of music and song and considering the view that such an endeavour will take forever, Franzon's (2008) definition of song will be taken as a working definition. Franzon's definition is considered suitable for this study since it not only addresses both the music and song aspects but also (just like Levinson's), realises the importance of performance. Franzon defines song as "a piece of music and lyrics - in which one has been adapted to the other, or both to one another - designed for a singing performance" (p.376). Hence, this definition addresses both music and song which are defined in terms of their purpose, which is performance. To Franzon, therefore, a song has three properties which are music, lyrics and prospective performance, and it is the prospective performance that determines the level of singability. However, it is also important to note that some songs (for instance an a capella) have only lyrics. Further explanation of music and song is provided by Griffee (1992) who defines songs as pieces of music that have words in them, such as popular songs and music as the sound produced by instruments such as an organ, flute or guitar. However, in this study, music alone (that is instrumental) is considered not beneficial to foreign language learning except if it is accompanied by lyrics, hence reference to both song and music rather than just music ${ }^{1}$. Hence, from now henceforth, the term song may be used to refer to both songs with music [as reflected in Franzon's (2008) definition of a song] and songs without instrument as reflected in the example of an acapella.

\subsubsection{Benefits of Using Songs in Foreign Language Learning}

\footnotetext{
${ }^{1}$ As in the case of Suggestopaedia, a teaching method propounded by Lozanow, where music is played on the background of various classroom activities and task so as to boost their concentration and memory (Bowen, 2002).
} 
Before engaging on how song projects can be implemented to promote foreign language learning, it would perhaps, be worthwhile to discuss various benefits of using music and songs in foreign language learning. The benefits of songs to foreign language learning far outweigh the limitations and many foreign language teachers seem to acknowledge this, yet it remains a mystery why only a few bother to incorporate music and song as a learning strategy in foreign language learning. The benefits of music and song include the following;

- Songs are a universal language

The interest in songs and music cuts across cultures. In other words, even though learners of a particular foreign language can have a limited knowledge of the target language cultural life, they can connect with songs and musicians from the target language community. Hence, choosing songs as a learning tool can create some familiarity which can raise learners' interest of learning the target language.

- Songs can motivate learners

Learning through songs also has been viewed as capable of improving the learning environment, relaxation and interest of learners. For instance, according to Kuśnierek, A. (2016), popular songs touch the lives of learners, and are connected with their various interests and everyday experiences. Popular songs address topics such as friendship, love, dreams, sorrow, learners easily connect with them and "since most young people nowadays are interested in a wide range of cultural forms outside classes, songs may be a really motivating and unique teaching tool" (p.24). Furthermore, a study conducted by Borisai and Dennis (2016) aimed at establishing the contribution of pop songs in promoting vocabulary learning by learners of English in Thailand, indicated that teaching new 
Music is a Gateway to the Soul...

vocabulary through pop songs motivated students in their learning of English.

Motivation has been viewed as the most used concept for explaining the failure or success of a second language or foreign language learner (Zareian and Jodaei 2015). Motivation thus, as Dörnyei (2005) puts it, "provides the primary impetus to initiate L2 learning and later the driving force to sustain the long and often tedious learning process..." (Dörnyei 2005: 65). Hence, if this is the case, songs can play an instrumental role in promoting foreign language learning.

- Songs improve learners' vocabulary learning skills

A number of scholars have conducted studies to determine the effectiveness of songs in helping learners to improve their vocabulary learning. Such studies (among others) include studies done by Burhayani (2013), Borisai and Dennis (2016) and Kuśnierek, A. (2016). These studies have therefore, established that due to their rhythmic properties, lyrics in songs are easy to memorise compared to other forms of texts such as long prose passages.

- Songs can act as a cultural database

Since most musicians sing about the everyday life in their surroundings, most songs tend to be detailed accounts of the cultural experiences of their communities. These accounts reflect not only the socio economical values of their period but also political views of the target language community, just as Chimurenga mbira ${ }^{2}$ music such as that of Thomas Mapfumo in Zimbabwe reflects not only a genre of cultural music that is unique to Zimbabwe, but also issues related to the liberation

\footnotetext{
${ }^{2}$ Songs and music about the liberation struggle in Zimbabwe played using mainly the mbira, an instrument made of a wooden board or a gourd with metal tines played by pressing the metals with one's thumbs and releasing them.
} 
struggle in Zimbabwe, (the $2^{\text {nd }}$ Chimurenga). Following this understanding, some scholars such as Kuśnierek (2016) add that songs provide edutainment, whereby language learning is presented as some form of fun activities. Learners can therefore, attain cultural knowledge of the target language while at the same time being entertained. Hence, while songs reflect the culture of the target language (Millington, 2011), this cultural data is transferred to learners in an entertaining way.

- Songs are an affordable resource

Compared to other materials that are used in foreign language classrooms such as textbooks, with the advancement of digitisation nowadays, getting access to various types of music online is one of the affordable experiences. Learners can download and share music through various online platforms such as iTunes.

- Songs improve learners' oral skills

By listening to songs, learners may develop their oral and listening skills (for instance see Lynch 2006 and Murphy 1992). Listening is as important as speaking, hence, without developing effective listening skills learners may struggle in their oral skills such as pronunciation. At the same time, learners may develop a communicative and pragmatic use of the target language which will help them to use the target language idioms and expressions in their appropriate contexts.

- Physiological benefits

First of all, if the view that songs create an atmosphere of feeling good (Dorrell 2005) and enjoyment (Millington 2011) is sustainable, then songs have the capability of transforming any foreign language classroom into a conducive environment that promotes productive learning. Secondly, beside the 
general aspects of feeling good and enjoyment, scholars have also alluded to the view that songs might have other specific physiological benefits such as lowered anxiety, blood pressure and heart rate, improving respiratory rate and recovery from tension (Salcedo 2010). Since anxiety ${ }^{3}$ (together with motivation and self-confidence) is considered as one of the affective factors which correlates with success in second and foreign language learning (Krashen 1981), lowering anxiety might lead to improved motivation levels and success in foreign language learning.

\subsubsection{Limitations of Using Music/Songs in Foreign Language Learning}

- Productive if well managed

While songs can be used as an effective way of promoting foreign language learning, without properly structured lesson plans, clear goals and assessment strategies they can merely provide listening pleasure rather than edutainment.

- Productive if learners are given autonomy

Since learners may not share the same song and music preferences, if learners are denied an opportunity to choose the genre of music they like, they can become less motivated or worse still; decide to be aloof from the classroom proceedings. However, this does not mean that lesson plans should be ignored; after all, Kuśnierek (2016) observes that teachers often complain that learners just want to listen, not work. Hence, the need for teachers to give learners autonomy to research and be creative while maintaining their role as the facilitators of their lessons. Millington (2011) suggests that

\footnotetext{
${ }^{3}$ Foreign language anxiety refers to anxiety related to foreign language learning and it is associated with emotional reactions of students towards language learning and acquisition (Horwitz, 2001)
} 
care should be taken when selecting songs since the language and sentence structure of some songs may be different from the common spoken form of the target. This is a valuable point, yet at another level, it can be argued that such songs actually demonstrate the "treasure"(Apter 2016: 15) within the target language. Hence, if learners are taught the treasures of the target language, they gain a communicative language competence level that is a privilege to most (uneducated) target language speakers.

\section{Theoretical Concerns}

\subsection{Translation}

What makes this study unique in contrast to most studies that deal with the issue of music and song in foreign and second language learning is that it advocates for a structured and planned utilisation of music through the means of translation and singability hence, translation is taken as the main trajectory through which the linguistic benefits of songs can be exploited to improve foreign language learning. It is therefore, important to introduce the concept of translation as a concept (through singability) that addresses theoretical concerns in this study. Since translation is a full-fledged field in Linguistics, only areas relevant to this study are going to be alluded to, mainly those that relate to translation of songs especially in the context of foreign language learning.

\subsubsection{Defining Translation}

In order to provide a befitting background to this section, a definition of translation may be needed. The general understanding of translation is a process of recreating a work of art which is written in one language (the source language) into another language (the target language). This is done "sensitively and seamlessly in such a way that it is true to the original" (Gill 2009: 1). In other words, the data transferred 
from one language to another have to carry its linguistic potency and meaning ${ }^{4}$. Translation therefore, as Newmark (1988) puts it, is usually (but not by any means always) considered as an action of "rendering the meaning of a text into another language in the way that the author intended the text" (p.5). The discussions of translation done by various scholars have demonstrated that translation is not a straight forward or one way activity. There are various complications and factors and avenues which can impact upon a translated work. For instance, Newmark pointed out that during translation, a text may be pulled in ten different directions, where issues such as whether the original author's style or idiolect should be preserved or modified to suit the target language reader/audience and how the translator handles source language cultural knowledge are considered. This view is reflected in the observation that "the role of a translator is many-faceted. He or she must hear the music of the original, and replay it for a new audience; a good translation sings, and displays a rhythm that not only reflects the original text's origin but also beats to a new drum"(Gill 2009: 1). Furthermore, the world views of the translator bordering on political, ethnic, religious, social class, sex matters may influence the end product. Translation traditions can also be influenced by various models that translators use. For instance some of these models include (but not limited to) the transformational model (which argues that in every language

\footnotetext{
${ }^{4}$ However, maintaining linguistic appeal and meaning in a "seamless" manner has over the years been proven to be one of the major challenges translators face, especially when translating works of fiction and other literary texts such as poetry and music where other factors such as rhythm and singability need to be taken into consideration. Such perspectives have led scholars such as Newmark (1988) to conclude that there is no such thing as a perfect, ideal or correct translation. In the same vein, Apter (2016) expresses the view that "all translation is a process of gain and loss, and it is not the translator's task to preserve any particular aspect of the original..." (p.15).
} 
there are areas of equivalence which can be manipulated to establish or transfer meaning) and the situational model of translation (which puts importance in the context specific pragmatic meaning that is provided by the source text).

\subsubsection{Translation in Foreign Language Learning}

While translation is clearly a valuable activity in any society, its relevance to foreign language learning has (over the years) been a subject of debate. Even though a number of issues have been raised to discredit the significance of translation in foreign language learning, a number of foreign language learners still desire to become translators. For instance, Stibbard (1994) observes that translation is usually overused and misused in foreign language classrooms due to a failure to understand the principles which must underlie it. He further postulates that, in some foreign language contexts such as in EFL (English as a Foreign Language), translation has been largely neglected. However, despite the criticism given to the role of translation in foreign language learning (see for instance, Guerra 2014), translation, as a growing field of research in foreign language learning is flourishing, and one cannot dismiss the view that most foreign language teachers (once in a while) still employ translation based tasks as a means of foreign language teaching.

\subsubsection{Limitations}

Perhaps the unfortunate draw back in the use of translation in foreign languages is engineered by models of foreign language teaching which are based on the concept of communicative language competence and the view that translation is related to the discredited method of language teaching known as the grammar -translation method (see for instance, Guerra 2014, p.154). Since the concept of communicative language competence advocates for situated pragmatic language use, 
activities that involve translation tend to be considered insignificant. However, such a perspective overlooks the fact that foreign language learning mainly takes place within the foreign language classroom, where such pragmatic language use has its limitations. Furthermore, the view that the learner's L1 and its culture are an undesirable element and that only target language should be used within foreign language classrooms (Pan \& Pan 2012) is unsustainable especially in cases where learners are adult beginners (for instance, in Zimbabwe, most learners of foreign languages in tertiary institutions are adult beginners) who do not have a background knowledge of the target language.

One of the most radical reviews of the significance of translation in foreign language learning is provided by Guerra (2014). According to Guerra, several scholars have lampooned the use of translation in foreign language learning citing the following arguments against it:

- That translation provides a simplistic one-to-one relationship between the learner's L1 and the foreign language, and such a relationship may promote linguistic interference.

- That translation is not a communicative task and therefore, has nothing to do with the communicative language approach, an approach preferred by most contemporary researchers and second and foreign language teachers.

- That translation has no value in the foreign language classroom, but rather in professional courses such as translation for professional purposes.

- That translation tasks are useless since they do not resemble real world practice, since translators normally operate into and not out of their mother tongue (Carreres 2006, in Guerra 2014). 
- That translation can be considered as a boring and nonstimulating activity (Duff 1989 in Guerra 2014).

These are some of the limitations levelled against translation in its application to foreign language learning. As argued at the beginning of this section, all of these can be challenged. However, the last point is a valued concern, especially if one has to consider that some foreign language teachers end up giving learners too much material to translate and it is such a tendency that Stibbard (1994) refers to as overuse and misuse. Giving too much translating material to learners can end up being counterproductive as learners may succumb to fatigue. However, in the context of song translation, translation activities especially those that involve performances may enhance students interest in the target language. After all, songs are usually short and precise and therefore, can provide manageable learning tasks for foreign language learners.

\subsubsection{Benefits}

As postulated above, together with other language teaching strategies, translation can be used as an effective tool of enabling foreign language learning. It is one of the objectives of this study to demonstrate that, as a strategy used together with songs, translation can indeed promote foreign language learning. For instance, translation establishes the relationship between the learner's L1 and the target language. This relationship does not necessarily need to be a one-to-one relationship but rather an account of points of contact and points of difference. The importance of this is that understanding the relationship between the two languages, learners can be able to avoid linguistic transfer. Learners need to understand the relationship that exists between their L1 and the target language. Furthermore, if extended beyond just translation of written material, translation can improve learners' oral skills. For instance, when translation activities 
Music is a Gateway to the Soul...

include direct translation, as one learner (or the teacher) speaks, another may translate.

Translation has a communicative purpose since it can expose foreign language learners to various kinds of material which represent real life situations (Guerra 2014). This is a valid point especially when translation models such as the situational model (which encourages the translator to understand contextual factors that give the original information meaning) are taken into consideration. When understood from this perspective, translation can afford foreign language learners a pragmatic target language experience.

\subsection{Translations of Songs}

In the same vein of discussing translation in foreign language learning, in order to keep with the objectives of this study, focus needs to be drawn towards translation of music and song material. The translation of songs especially in the context of foreign language learning is not a common subject of discussion. In fact, unlike literary works such as poetry and novels, the amount of available literature that deals with song translation is not encouraging. This observation is also highlighted in the work done by Franzon (2008), who expresses the view that until recently, attention given to songs was done by professional translators and not much attention was given to this form of translation by scholars of Translation Studies. Furthermore, the meagre amount of studies that deal with song translation may be instigated by challenges that arise from dealing with such studies (Susam-Sarajeva (2008). This is beside the observation by some scholars (e.g. Apter 2016: 19) that these challenges also present opportunities. What makes translation of music and songs complex is that there are multiple options that translators may choose to employ during the translation process and the outcome of the product depends 
upon these options. Some of these options are outlined by Franzon (the five options) and are going to be discussed below. Furthermore, as observed by Susam-Sarajeva (2008), the translation of music and song is an interdisciplinary activity which needs researchers to be conversant with other related areas such as musicology and media study in order to conduct convincing investigations.

\subsubsection{Singability: Franzon (2008)}

The concept singability which is an important aspect of song translation is central in this study. A recap of the definition of song provided by Franzon states that a song is "a piece of music and lyrics - in which one has been adapted to the other, or both to one another - designed for a singing performance"(p.376). Hence, central in this definition is the purpose of a song; which is performance. In this light, the singing performance cannot be performed if the translated version of the song is unsingable. Unsingable therefore, means unperformable (p.375). While admitting that the term singability is ambiguous, Franzon proceeds to state that:

As a term, singability can be understood in a restricted way, as referring mainly to phonetic suitability of the translated lyrics: to words being easy to sing to particular note values (as in Low 2005:192-94). Yet the term can also be used in a broader sense. It can be used to assess original lyrics as well as translations (p.374).

In the context of this study, that is in its use in relation to music and song projects in foreign language learning, the term will be used to refer to "words being easy to sing" without any particular restriction when it comes to the instrumentation, as long as the words keep some form of rhythm and can be performable. 
The aspect of singability can therefore, be added as another factor that differentiates song translation from other forms of translation such as literary translation, since the translator will not only be dealing with words but also with rhythm and rhyme. In this light, Franzon proposes five avenues that a translator can take during the process of translating a song. These are;

- Leaving the song untranslated, in other words keeping the original version intact;

- Translating the lyrics but ignoring the music;

-Writing new lyrics to the original music with no overt relation to the original lyrics;

- Translating the lyrics and adapting the music accordingly sometimes to the extent that a brand new composition is deemed necessary;

- Adapting the translation to the original music.

In the context of implementing music and song projects in foreign language learning, all the five options can be attempted as long as the products are performable. For instance, the third option is considered only to support creative performance within the foreign language classroom. After all, Low (2005) lampoons such tendencies by stating that:

Some people ignore sense altogether: they take a foreign song tune and devise for it a set of TL words which match the music very well but bear no semantic relation with the ST. While this may at times be good and appropriate, it is not translating, because none of the original verbal meaning is transmitted. Such practices have no place in discussions of translation (p.194).

Hence, the diversion from the original meaning of the song may only be entertained if it is done as a way of exploring further use of the target language and also as a way of 
capturing creativity and autonomy of foreign language learners.

\subsubsection{The Pentathlon Principle: Low (2003, 2005)}

Peter Low is one of the scholars who has made an immense contribution in this challenging field of music and song translation. The discussion on singability would not be complete if reference to his pentathlon principle is not alluded to, especially considering the fact that it is the first and evidently most important of the five principles outlined in the Pentathlon Principle hypothesis. Low (2005) argues that translating songs needs to be considered as a pentathlon, with five key principles whose balance needs to be maintained. These principles are: Singability, Sense, Naturalness, Rhythm, and Rhyme. In relation to the first principle which is singability, Low (2003) notes that a singable song translation maintains performability. It must function effectively as an oral text delivered during performance, unlike in the case of a written text that is not meant for performance and where the reader decides how to read it. Furthermore, a singable text has to highlight other aspects crucial for performance such as high pitched or low words where necessary. Sense refers to the meaning of original text. Evidently, Low considers song translation that diverts from the original meaning of the text or rather ignores the principle of sense as not translation at all (Low, 2005). Naturalness refers to the presentation of the original song in its natural and untransformed manner. This follows the view that when translating, translators need to be influenced by the source language rather than their "native" language. Rhythm refers to the tempo of the song, whether it is slow or fast and Rhyme refers to a rhyme scheme (such as the end rhyme preferred by most rappers which is also important in establishing singability). 
However, although Low encourages translators to keep a balanced check of all five principles, sometimes, such an approach depends on context and purpose of a performance. For instance, if song translation is done in the context of foreign language learning, which is not big movie performance, how one prioritises his or her principles becomes immaterial as long as the end product is singable and an oral performance of the target language is done. However, this observation does not attempt to take away the significance of the Pentathlon Principle. It remains a valuable resource in song translation.

\subsubsection{Singability: Significance in Music/Song Projects}

What makes singability vital in this study is the consideration that music and song projects need to be performed in order to create a conducive and relaxed environment for foreign language learning. Secondly, these projects need to demonstrate a transformation in translation. That is, they need to combat the issue of boredom and lack of motivation (see for instance Duff 1989 in Guerra 2014) that is usually levelled against traditional translation. Advocating for performance based song project can therefore, captivate learners to participate in classroom activities. After all, "perhaps the greatest benefit of using songs in the classroom is that they can be fun. Pleasure for its own sake is an important part of learning a language, something which is often overlooked by teachers" (Millington 2011: 134-135).

Thirdly, the principle of singability can be utilised by foreign language teachers to encourage and tape out creativity among learners. Creativity is correlated to foreign language motivation and improved performance and proficiency level (see for instance, Nosratinia 2014). Lastly, through singability and other related principles of the Pentathlon Principle such as 
Rhythm, and Rhyme, which can aid in the memorisation of the target language, foreign language learning can be promoted, especially in relation to the acquisition of vocabulary and target language idioms.

\section{Music/Song Projects: Implementation}

This section focuses on the implementation process of music and song projects and therefore, deals with pedagogic suggestions and strategies that can be implemented as a way of utilising songs in foreign language learning. The suggestions provided here are not exhaustive but rather open up a platform for further engagement and research in how songs can be harnessed to bring out the best in foreign language learners. Some of these suggestions may largely depend upon particular teaching methods used by teachers, as such, it will be the task of the language teachers to ensure that suggestions provided here tally with their foreign language teaching methods. This is done in order to ensure that productive target language learning is achieved. Furthermore, the author of this study can find it irresistible to draw examples from the experience of learning German as a foreign language $(D a F)$ since it is his line of expertise. However, similar illustrations can be drawn from other modern foreign languages such as French, Portuguese, and Chinese (inter alia).

\subsection{Class Arrangement}

First of all, since music and song projects are not the usual tool through which foreign languages are taught in many contexts, they present new challenges; for instance, when it comes to the classroom learning arrangements. It therefore becomes imperative for foreign language teachers to establish class arrangements which allow learners to perform at their best level. Evidently, since these projects involve translation activities and teachers might desire to minimise boredom, 
basing them on individual tasks may not achieve much. The suggestion given here therefore is that, in order to maximise on the gains of music and song projects, teachers need to consider adopting group arrangements such as pair and small group work. The main reason behind this suggestion is that the success of music and song projects depends on performance and working together. It can be a motivating force for learners. When a song is performed by a group, each learner is given a role to play (learners themselves decide who sings which part) and the rehearsed product is performed in front of the class. With individuals being only responsible for a particular part of the song, they are likely to memorise it well and learn it by heart. In their presentations, groups can be encouraged to compete against one another.

\subsection{Resources and Performance}

Learners need to be advised as to where they can find material for their projects. While a few songs can be found in their language textbook, however, when it comes to song material, language textbooks do not provide much. Resources can be found in three categories;

\section{Category I: Popular L1/L2 Music Sung in the Target Language}

With the advancement of both digitization and globalisation, there is a growing culture to avail material that was scarce before to almost everyone who is willing to get it. Music is not spared of this culture. In literature, great works of art have been translated to many other languages to enable them to penetrate every society of the world. In music too, there is a growing tendency to translate and perform popular music to ensure that everyone drinks it using his or her own cup. There is therefore, tones and tones of popular music performed in the target language of choice. For instance, a learner of German as 
a foreign language in an English speaking community may be impressed by a site such as the one with the title: "10 Great German Versions of English Language Songs"5. This site presents German versions of popular songs originally done by singers and performers such as the Beatles, and David Bowie among others. Interestingly, the actual learning of the target language (in this case German) begins with the title. For instance, Sie lebt dich, a German version of "She Loves You" by Beatles. However, in order to gain from the song performances of this nature, learners are encouraged to perform both versions of the song, that is both in the L1/L2 (e.g. English) and the target language (e.g. German). Since it has already been mentioned that group work is the best arrangement for music and song projects, a group can divide itself into two, where one half deals with target language version and the other half performs the original version of the song.

\section{Category II: Popular Target Language Music Sung in the L1/L2}

The second category covers popular songs in the target language which can be translated and performed both in the original and the translated version. Examples in the context of learning German as a foreign language can be provided with names such as Herbert Grönemeyer, a musician and actor popping up. Grönemeyer is well-known for his role in the movie Das Boot (1981), where he starred as Lt. Werner. He is well known for albums such as 4630 Bochum and Mensch. His songs such as Zum Meer (To the Sea) and Der Weg (The Way) can be utilised for the purposes of foreign language learning under this category. These songs can be performed first and

\footnotetext{
${ }^{5}$ This is available here: https://theculturetrip.com/europe/germany/articles/10-greatgerman-versions-of-english-language-songs/
} 
foremost in their original versions followed by a translated version in the L1/L2. Group work distribution suggested under the first category can also be applied in the second and third categories. Since learners are encouraged to start by performing songs in this category in their original form, this resonates well with the Franzon's (2008) first choice of "Leaving the song untranslated".

\section{Category III: Songs Derived from the Target Language Texts}

The third and final category seeks to encourage learners to be creative. It encourages them to use the available language learning material to pick out particular texts and use this content to compile a song. Just like in the second category, songs in this category need to be performed first and foremost in the target language and followed by a translated version of the songs. In this category, learners will be faced with two challenges; the challenge of merging ideas into a song compilation and the challenge of blending the text into a rhythmic product. However, it is such productions that can bring out all the fun and can reflect a display of talent such as in America's or South Africa's Got Talent show.

In relation to performance, learners need to be given autonomy when considering how to present their product. Some can decide to present their song in acapella versions or beatbox, while some may use various music editing tools and applications in presenting their final product. Teachers need to provide others resources such as computer speakers (some media centres are well-equipped for such performances, e.g. language media centre at the University of Zimbabwe). Furthermore, during the day of performance, the performers need to avail a printout of the lyrics of their songs. 


\subsection{Assessment}

Since music and song projects are meant to provide edutainment, foreign language teachers need not to forget assessing the benefit of these projects. For instance, in the context of the integrated language and Culture mode of instruction, assessment can be divided into two taxonomies; that which deals with assessment of target language details and the second category which deals with assessment of details of cultural significance. Hence, every performance needs to be assessed based on these two categories.

\section{Conclusion}

In summation, this article explores the significance of music and song projects in promoting foreign language learning. The method of approach that is taken by this article is unique since the paper argues that for music and song projects to bring forth productive foreign language learning, performance should be taken as the key. Performance is therefore, necessitated by both translation and most importantly the element of singability. The discussion therefore, revolves around the perspective that songs can be potent tools of foreign language learning if the concepts of translation, singability and performance are considered vital. The article therefore, discusses the role that songs play in foreign language learning, before exploring translation and how it can be utilised to bring out the best out of the use of songs in the foreign language classroom. The article goes on to discuss the concept of singability and how it is related to the important aspect of performance. The study concludes by providing implementation strategies and suggestions of how music and song projects can be utilised to bring out the best in foreign language learners. These strategies and suggestions are based 
Music is a Gateway to the Soul...

on class arrangement, resources and performance and assessment.

\section{References}

APTER, R.; and HERMAN, M. 2016. Translating for Singing: The Theory, Art, and Craft of Translating Lyrics. London: Bloomsbury Publishing Plc.

Borisai, T,; and Dennis, N. K. 2016. A Study of Using Pop Songs to Promote New Vocabulary Learning for Secondary School Students. International Journal of Research, 4(1). 8692.

Bowen, T. 2002. What is Suggestopedia? Macmillan Publishers Ltd.

http://www.onestopenglish.com/News/MagazineArchive/ suggesta.htm

Brown, D. H. 2000. Teaching by Principles: An Interactive Approach to Language Pedagogy (2nd Ed.). New York: Longman.

BuRHAYANI, E. 2013. Teaching Vocabulary Through Songs. 2nd International Seminar on Quality and affordable Education (ISQAE 2013).

DÖRNYEI, Z. 2005. The Psychology of the Language Learner: Individual Differences in Second Language Acquisition. New Jersey: Lawrence Erlbaum Associates.

DorRell, P. 2005. What is Music? Solving a Scientific Mystery. http://whatismusic.info/. (Retrieved: 30 September 2017).

FRANZON, J. 2008. Choices in Song Translation: Singability in Print, Subtitles and Sung Performance. The Translator, 14(2). 373-399.

Gill, P. (ed.). 2009. Translation in Practice. A Symposium. Champaign and London: Dalkey Archive Press.

GrIFFEE, D. T. 1992. Songs in Action. Trowbridge: Prentice Hall International. 
GuerrA, F. A. 2014. The Usefulness of Translation in Foreign Language Learning: Students' Attitudes. ELT journal, 2(1). 153-170.

Horwitz, E. K. 2001. Language Anxiety and Achievement. Annual Review of Applied Linguistics 21. 112-126.

KhaghanineJAD, M. S,; and FAHANDEJSAADI, R. 2016. Music and Language. Retrieved from: https://www.researchgate.net/publication/307014316.

(Retrieved: 25 September 2017).

Krashen, S. D. 1981. Second Language Acquisition and Second Language Learning. Pergamon: Pergamon Press Inc.

KuŚNIEREK, A. 2016. The Role of Music and Songs in Teaching English Vocabulary to Students. World Scientific News 43(1). $1-55$.

LeE, L, and Lin, Shu-ChuAn. 2015. The Impact of Music Activities on Foreign Language, English Learning for Young Children. Journal of the European Teacher Education Network 10. 13-23.

LeVInson, J. 1990. Music, Art, and Metaphysics. Ithaca: Cornell University Press.

Low, P. 2003. Singable Translations of Songs. Perspectives 11(2). 87-103.

Low, Peter. 2005. The Pentathlon Approach to Translating Songs. In Gorlée, D.L. (ed). Song and Significance. Virtues and Vices of Vocal Translation. New York: Rodopi. 185-212. Low, P. 2008. When Songs Cross Language Borders. The Translator 19(2). 229-244.

Millington, N. T. 2011. Using Songs Effectively to Teach English to Young Learners. Language Education in Asia 2(1). 134-141.

Murphey, T. 1992. Music \& Songs. Oxford: Oxford University Press.

NeWmark, P. 1988. A Textbook of Translation. Shanghai: Shanghai Foreign Language Education Press. 
Music is a Gateway to the Soul...

NosRatiniA, M. 2014. Creativity and Language Learning Strategies: Toward a More Successful Language Learning. International Journal of Scientific \& Engineering Research. 5(2). 1156-1170.

Pan, YI-CHUN; and YI-CHING PAN. 2012. The Use of Translation in the EFL Classroom. The Philippine ESL Journal 9. 4-23.

SALCEDO, C. S. 2010. The Effects of Songs in the Foreign Language Classroom on Text Recall, Delayed Text Recall and Involuntary Mental Rehearsal. Journal of College Teaching \& Learning 7(6). 19-30.

STIBBARD, R. 1994. The Use of Translation in Foreign Language Teaching. Studies in Translation Theory and Practice 2(1). 918.

StOPAR, A. 2016. Mamma Mia, A Singable Translation! Translation Studies 13(1). 141-159.

ZAREIAN, G.; and JodAeI, H. 2015. Motivation in Second Language Acquisition: A State of the Art Article.

International Journal of Social Science and Education 5(2). 295-308. 